\title{
Exercise induced atrio-ventricular (AV) block during nuclear perfusion stress testing: a case report
}

\section{Blocco atrio-ventricolare indotto dall'esercizio durante durante scintigrafia perfusionale miocardica: descrizione di un caso}

\author{
Filippo Maria Sarullo, Salvatore Accardo, Paola D’Antoni1, Annamaria Martino, \\ Antonio Micari2, Vincenzo Pernice2, Antonio Castello
}

\begin{abstract}
Exercise induced atrio-ventricular (AV) block during nuclear perfusion stress testing: a case report. F.M. Sarullo, S. Accardo, P. D'Antoni, A. Martino, A. Micari, V. Pernice, A. Castello.

Background. Exercise causes enhanced sympathetic discharge and results in physiologic tachycardia. However, in some patients with a diseased conduction system resulting from acute ischemia, exercise can precipitate heart block.

Methods and results. In this report we describe a 51 years old male patient with transient advanced degree atrioventricular (AV) block developed during recovery from exercise stress testing, resolved after the administration of atropine. Nuclear perfusion imaging demostrated stress-in-
\end{abstract}

\begin{abstract}
duced ischemia of the inferior-apical segments, and recovery of perfusion in the images obtained at rest. Coronarography showed critical stenosis of the right coronary artery, which was treated by percutaneous coronary intervention (PCI) and drug eluting stent (DES) deployment.

Conclusion. Nuclear myocardial perfusion imaging provides noninvasive evidence that transient ischemia of the infero-apical segment can result in advanced degree $\mathrm{AV}$ block in patient with critical severe right coronary disease.

Keywords: atrio-ventricular block, nuclear myocardial perfusion imaging, exercise stress testing.
\end{abstract}

Monaldi Arch Chest Dis 2008; 70: 29-33.

Department of Cardiology - Buccheri La Ferla Fatebenefratelli Hospital, ${ }^{1}$ Medicina Nucleare s.r.l., and ${ }^{2}$ Emodinamic Service Villa Maria Eleonora Hospital - Palermo, Italy.

Corresponding author: Filippo Maria Sarullo MD.; Department of Cardiology - Buccheri La Ferla Fatebenefratelli Hospital; Via Salvatore Puglisi, 15 - I-90143 Palermo (Italy); E-mail: fsarullo@neomedia.it

\section{Introduction}

Exercise causes enhanced sympathetic discharge and results in physiologic tachycardia. However, in certain patients with a diseased conduction system resulting from acute ischemia, exercise can precipitate heart block. The sinus and atrioventricular nodes are innervated by the autonomic nervous systems. The His-Purkinje system is relatively devoid of autonomic nerve supply. Hence the former and not the latter is more influenced by autonomic stimulation. During exercise, conduction improves across the atrioventricular node which can stress the His-Purkinje system and lead to heart block in those with significant His-Purkinje disease. In this report, we discuss a case of exercise-induced transient advanced degree atrio-ventricular (AV) block, in which nuclear perfusion imaging was obtained simultaneously with block appearance, demonstrating reversible ischemia of the inferoapical segment.

\section{Case report}

A 51-years old man, obese, with a history of hypercolesterolemia and family history of coronary artery disease (CAD) underwent a routine nuclear exercise stress test. His physical examination, chest radiography and routine laboratory test, including two-dimensional echocardiography, were normal. A standard 12-lead electrocardiogram (ECG) revealed normal synus rhythm at a rate of $73 / \mathrm{min}$ with normal 1:1 AV conduction (PR interval $120 \mathrm{msec}$; fig. 1). A maximal or symptom-limited treadmill exercise test (ET) according to the Bruce protocol (Marquette Hellige CardioSoft V3.03, USA) was performed. Approximately 1 minute before the termination of the ET, an intravenous dose of $740 \mathrm{MBq}$ of $99 \mathrm{~m}$ technetium tetrofosmin was administered. During the second recovery minute, ischemic changes in D1, aVL and V4-V6 leads appeared and a complete symptomatic (dizziness) AV block occurred, with idioventricular rhythm at $30 \mathrm{bpm}$, lasting 80 seconds (fig. 2). Dizziness and progressive restoration of 1:1 AV conduction resolved after atropine therapy $(1 \mathrm{mg})$ in two minutes (fig. 3). SPECT stress images demonstrated a wide infero-apical defect; rest scan, obtained two days later, showed a recovery of perfusion in the infero-apical segments (fig. 4). Subseguent coronary angiography showed critical stenosis of the right coronary artery (RCA), which was treated by percutaneous coronary intervention (PCI) and drug eluting stent (DES) deployment (fig. 5-6). 


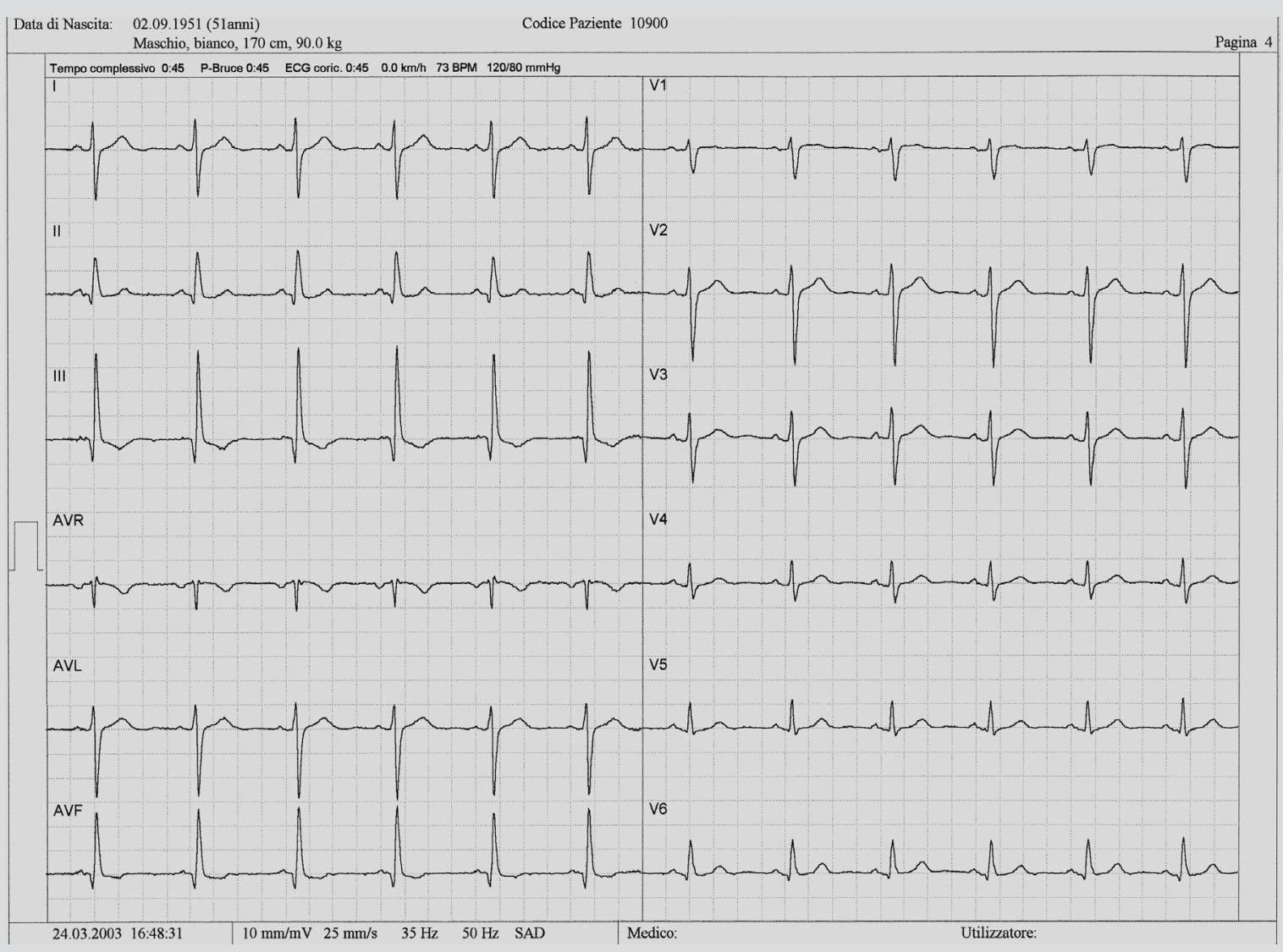

Figure 1. - Pre-test standard 12-lead electrocardiogram (ECG).

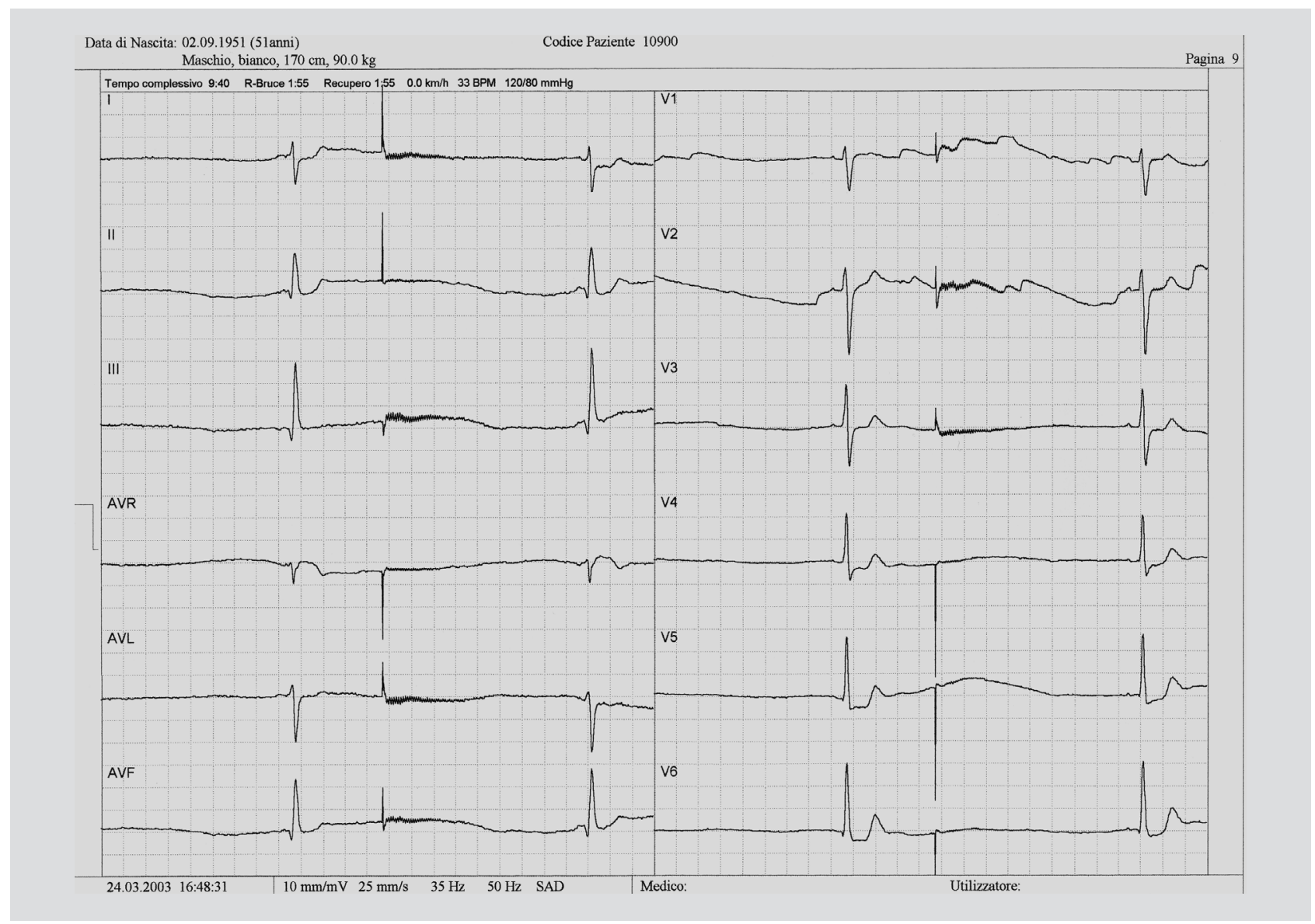

Figure 2. - ECG at the second recovery minute: ischemic changes in D1, aVL and V4-V6 leads appeared and a complete symptomatic (dizziness) AV block occurred, with idioventricular rhythm at $30 \mathrm{bpm}$. 


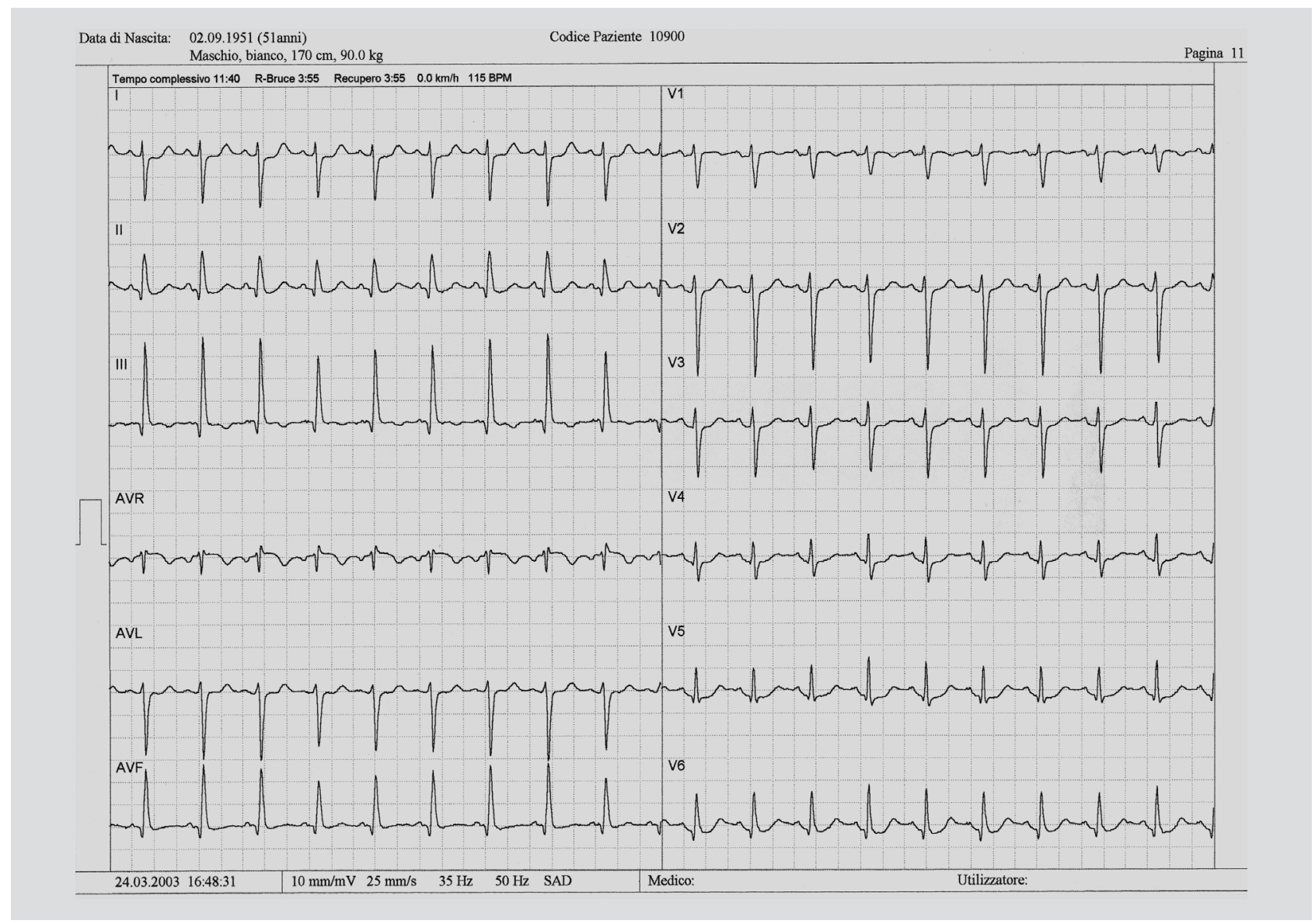

Figure 3. - ECG at the fourth recovery minute: restoration of 1:1 AV conduction after atropine therapy $(1 \mathrm{mg})$.

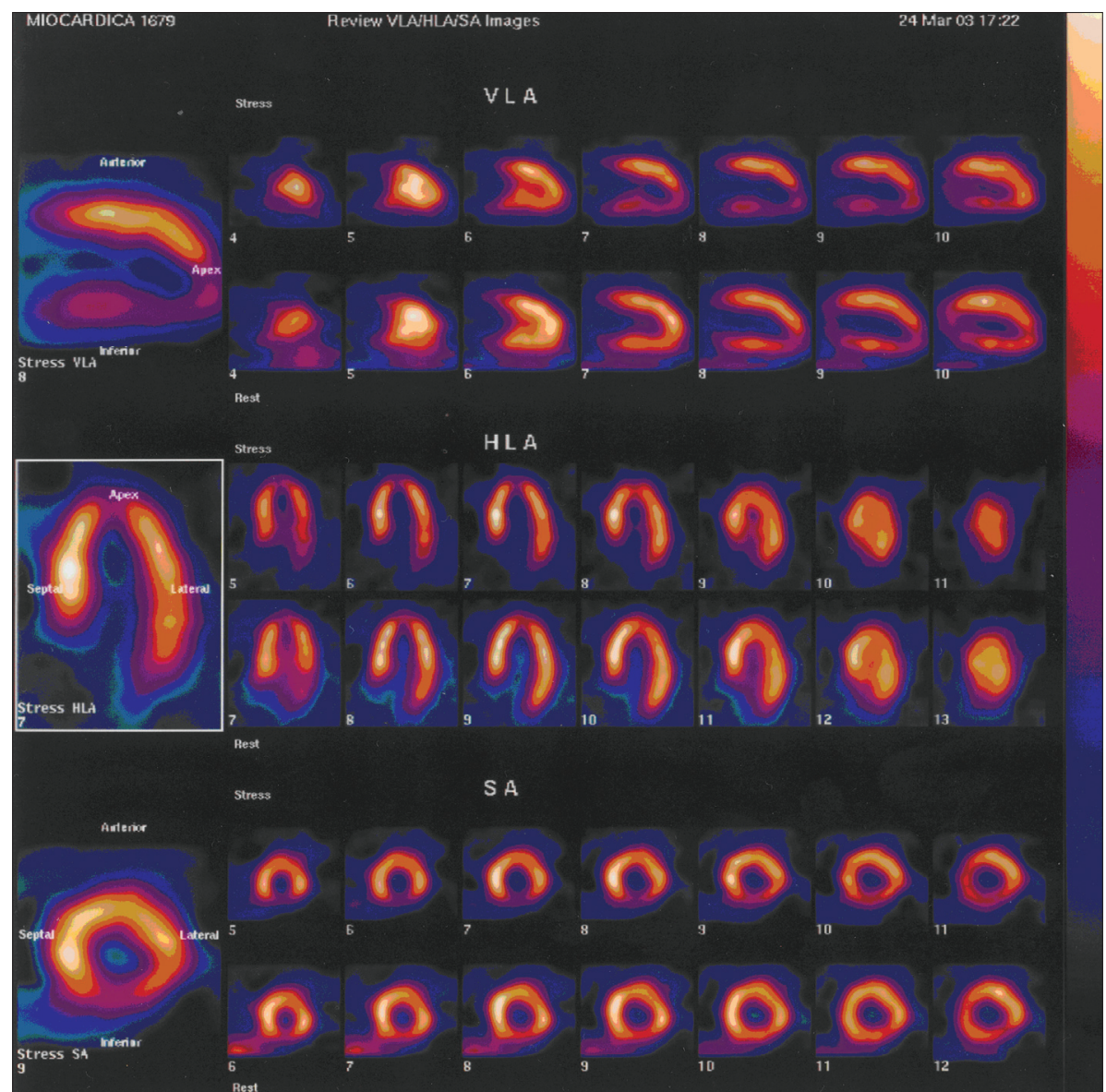

Figure 4. - Myocardial perfusion SPECT stress images demonstrated a wide infero-apical defect; rest scan, obtained two days later, showed a recovery of perfusion in the infero-apical segments.
One year after PCI + DES exercise stress test was repeated with the same Bruce protocol. Block did not recur and the patient remained symptom-free during the follow-up.

\section{Discussion}

Experimental studies in animals have demonstrated that excitation of vagal sensory nerve endings from myocardial ischemia involving the inferoposterior wall of the left ventricle activates potent cardioinhibitory reflex resulting in bradycardia and hypotension [1,2]. In humans, similar observations have been made under particular conditions of severe transmural inferior ischemia and its reperfusion, such as those occurring with myocardial infarction, vasospastic angina, or angioplasty of the right coronary artery [3-7]. Despite these well-recognized clinical observations, little attention has been paid to the question 


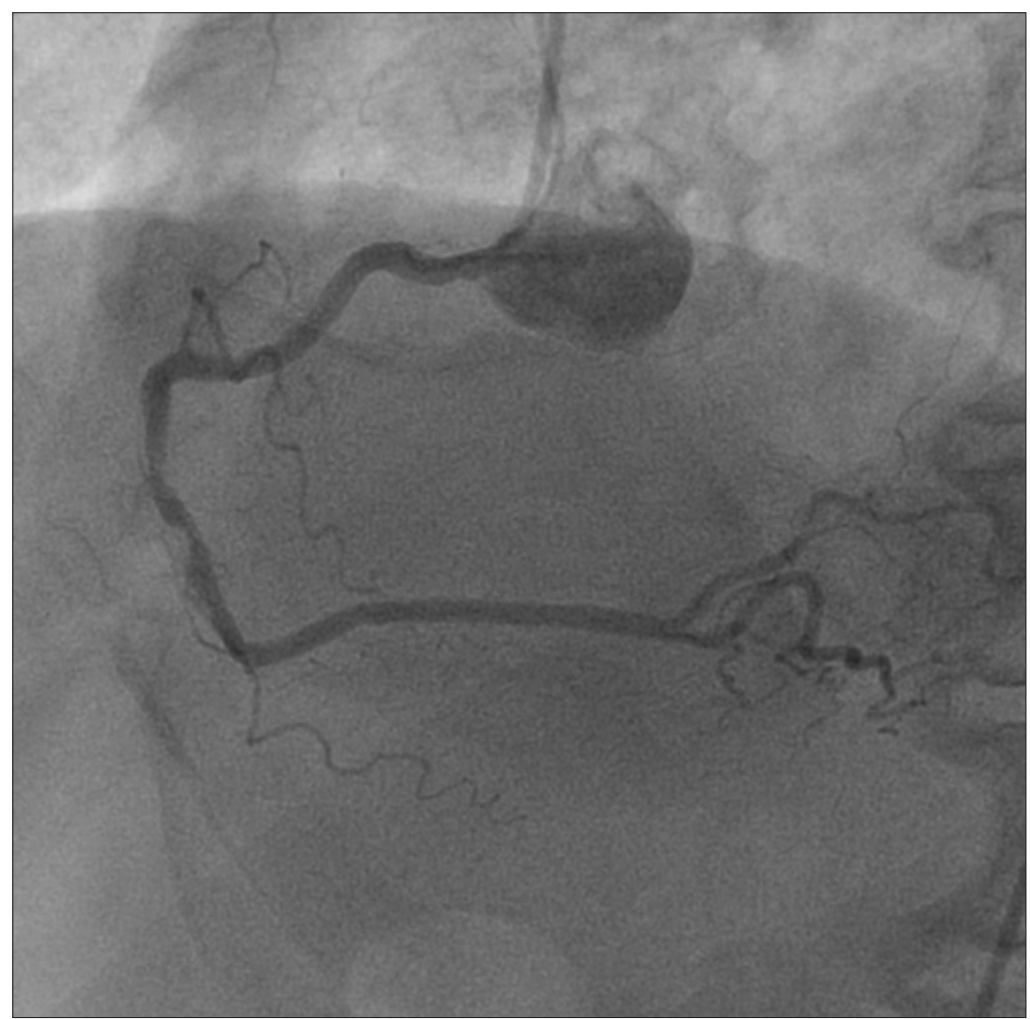

Figure 5. - Coronary angiography showed critical stenosis of the right coronary artery (RCA).

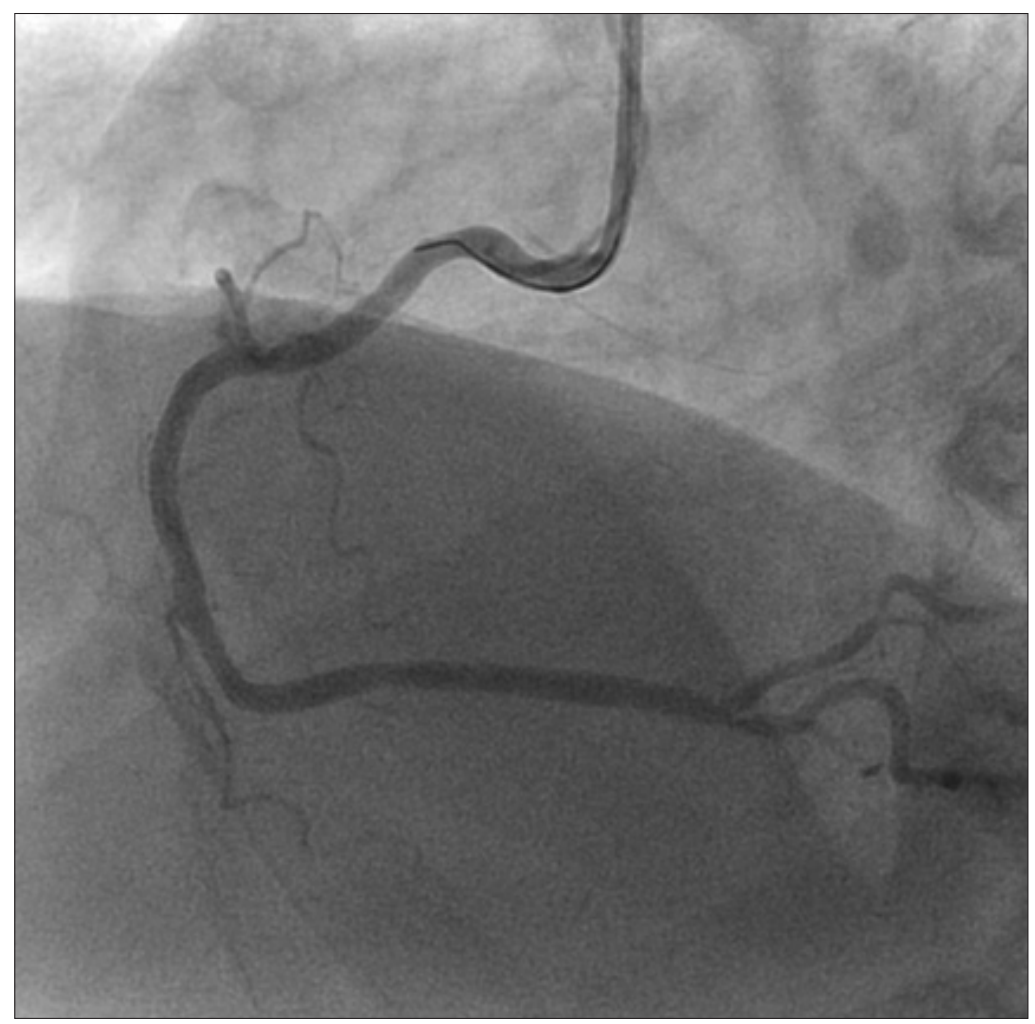

Figure 6. - Coronary angiography after percutaneous coronary intervention (PCI) and drug eluting stent (DES) deployment.

as to whether this reflex could be evoked by exercise-induced ischemia that is usually subendocardial with the manifestation of ST depression and that might be recurrently experienced during daily activities [8-11]. The present case indicated that exerciseinduced subendocardial ischemia may augment vagal activity and may evoke the cardioinhibitory reflex, which would in turn influence postexercise heart rate decay. This is in agreement with Tahara et al. [12] that reported on fifty-two patients who developed sinus deceleration during exercise testing, all of whom had angiographically documented RCA lesion. The authors speculated the role of Bezold-Jarisch reflex in this mechanism and stated that the prevalence of deceleration during exercise appears to be very low. Sinus deceleration during exercise may be an extreme example caused by an ischemia-mediated reflex $[13,14]$.

Thus this reflex phenomenon is presumably operative during exercise-induced ischemia as well as during post exercise reperfusion; however, we focused on post exercise heart rate dynamics for the following reasons. Since vagal activity is physiologically attenuated in proportion to the increase in exercise intensity, this reflex might be masked during exercise. In contrast, potent reactivation of vagal nerve activity after exercise may accelerate the appearance of this reflex under a higher vagal condition after exercise. The physiological implication of this reflex, namely, what role this reflex may play, is unknown. The possibility that the reflex cardioprotectively works thorough the reduction in myocardial oxygen demand or that the resultant high vagal tone prevents the development of serious ventricular arrhythmias is of interest $[15,16]$; however, there are few available data to support this so far.

In conclusion, we can consider that the vagal over-activation after exercise may be useful in predicting the presence of inferior ischemia when significant exercise-induced ST depression are observed. It may also be useful in patients after angioplasty of RCA to predict restenosis or to confirm the therapeutic effects.

\section{Riassunto}

Introduzione. Durante l' esercizio fisico si verifica una complessa serie di eventi che permette al cuore di aumentare la sua funzione di pompa. Il più importante di questi meccanismi è l' incremento della frequenza cardiaca, attraverso l'attivazione del sistema simpatico. Tuttavia, in alcuni pazienti con una malattia del sistema di conduzione secondaria ad ischemia miocardica acuta, l' esercizio fisico può determinare l' insorgenza di un disturbo di conduzione tipo blocco atrio-ventricolare all'ECG di superficie.

Materiale e metodi. Riportiamo il caso clinico di un maschio di 51 anni di età, che durante la fase di recupero di un test da sforzo condotto al tappeto rotante secondo il protocollo di Bruce, ha presentato 
l'insorgenza di un blocco atrio-ventricolare avanzato, risolto con la somministrazione di atropina e l'infusione endovenosa di liquidi.

Lo studio perfusionale miocardico condotto con metodica scintigrafica GATED-SPECT, mostrava un difetto reversibile a carico dei segmenti inferoapicali del ventricolo sinistro. La coronarografia successiva metteva in evidenza una stenosi critica della arteria coronarica destra, trattata con angioplastica percutanea ed applicazione di stent medicato.

Conclusioni. Nel caso presentato, la scintigrafia miocardica di perfusione ha permesso di mettere in evidenza una sofferenza ischemica miocardica transitoria associata ad un blocco atrio-ventricolare avanzato all'ECG di superficie, in un paziente con severa patologia aterosclerotica della coronaria destra.

\section{References}

1. Felder RB, Thames MD. Interaction between cardiac receptors and sinoaortic baroreceptors in the control of efferent cardiac sympathetic nerve activity during myocardial ischemia in dogs. Circulation Res 1979; 45: 728-736.

2. Thames MD, Klopfenstein HS, Abboud FM, Mark AL, Walker JL. Preferential distribution of inhibitory cardiac receptors with vagal afferents to the infero-posterior wall of the left ventricle activated during coronary occlusion in the dog. Circulation Res 1978; 43: 512-519.

3. Koren G, Weiss AT, Ben-David Y, Hasin Y, Luria MH, Gotsman MS. Bradycardia and hypotension following reperfusion with streptokinase (Bezold-Jarisch reflex): a sign of coronary thrombolysis and myocardial salvage. Am Heart J 1986; 112: 468-471.

4. Mark AL. The Bezold-Jarisch reflex revisited: clinical implication $\mathrm{s}$ of inhibitory reflexes originating in the heart. J Am Coll Cardiol 1983; 1: 90-102.

5. Prez-Gomez F, Martin de Dios R, Rey J, Aquado AG. Prinzmetal's angina: reflex cardiovascular response during episode of pain. Br Heart $J$ 1979; 42: 81-87.
6. Robertson RM, Robertson D. The Bezold-Jarisch reflex: possible role in limiting myocardial ischemia. Clin Cardiol 1981; 4: 75-79.

7. Wei JY, Markis JE, Malagold M, Braunwald E. Cardiovascular reflexes stimulated by reperfusion of ischemic myocardium in acute myocardial infarction. Circulation 1983; 67: 796-801.

8. Finzi A, Bruno A, Perondi R. Exercise induced paroxysmal atrio-ventricular block during nuclear perfusion stress testing: evidence for transient ischemia of the conduction system. G Ital Cardiol 1999; 29: 1313-1317.

9. Egred M, Jafary F, Rodrigues E. Exercise induced atrioventricular (AV) block: important but uncommon phenomenon. Int J Cardiol 2004; 97: 559-560.

10. Yuzuki Y, Horie M, Makita T, Watanuki M, Takahashi A, Sasayama S. Exercise induced second-degree atrioventricular block. Jpn Circ J 1997; 61: 268-271.

11. Hemann BA, Jezior MR, Atwood E. Exercise-induced atrio-ventricular block: a report of 2 case and review of the literature. J Cardiopul Rehabil 2006; 26: 314-318.

12. Tahara N, Takaki H, Taguchi A, Suyama K, Kurita T, Shimizu W, Miyazaki S, Kawada T, Sunagawa K. Pronounced HR variability after exercise in inferior ischemia: evidence that the cardioinhibitory vagal reflex is invoked by exercise-induced inferior ischemia. $A m J$ Physiol Heart Circ Physiol 2005; 288: H1179-H1185.

13. Chokshi SK, Sarmiento J, Nazari J, Mattioni T, Zheutlin T, Kehoe R. Exercise provoked distal atrio-ventricular block. Am J Cardiol 1990; 66: 114-116.

14. Coplan NL, Morales MC, Romanello P, Wilentz JR, Moses JW. Exercise related atrio-ventricular block: influence of myocardial ischemia. Chest 1991; 100: 17281730.

15. Huikuri HV, Valkama JO, Airaksinen KEJ, Seppanen T, Kessler KM, Takkunen JT, Myerburg RJ. Frequency domain measures of heart rate variability before the onset of non-sustained and sustained ventricular tachycardia in patients with coronary artery disease. Circulation 1993; 87: 1220-1228.

16. Pedretti R, Etro MD, Laporta A, Braga SS, Carù B. Prediction of late arrhythmic events after acute myocardial infarction from combined use of non-invasive prognostic variables and inducibility of sustained monomorphic ventricular tachycardia. Am J Cardiol 1993; 71: 1131-1141. 